\title{
Increasing renewable penetration on islanded networks through Active Network Management: a case study from Shetland
}

Simon Gill ${ }^{1}$, Michael Dolan², Abdullah Emhemed ${ }^{1}$, Ivana Kockar ${ }^{1}$, Malcolm Barnacle ${ }^{1}$, Graham Ault², Colin Mathieson ${ }^{3}$

\section{Abstract}

The drive to reduce reliance on fossil fuel generation in meeting power system demand is encouraging network operators to develop novel methods of making greater use of available network capacity whilst maintaining stability and security. Challenges relating to network stability are particularly acute on islanded networks. The Northern Isles New Energy Solutions (NINES) project is implementing novel techniques for managing the power network on the Shetland Islands in the UK. Active Network Management is used to monitor and control the network and new wind generation in real time, and flexible demand is scheduled to minimise the use of conventional generation by reducing wind curtailment and minimising system losses. The flexible demand devices deployed also have the ability to respond to frequency therefore supporting system stability. This paper presents the development of two novel modelling techniques used in the design and deployment of NINES - an 'envelope of stability wind generation' and the use of Dynamic Optimal Power Flow to schedule flexible demand. A case study is presented which shows that an ANM scheme managing flexible demand has the potential to increase wind capacity connected on Shetland from the existing $4 M W$ to 16.1MW. The management of domestic demand flexibility is shown to contribute up to 6.5GWh towards the reduction in conventional generation or up to $16.6 \mathrm{GWh}$ if domestic demand provides frequency response.

\footnotetext{
${ }^{1}$ University of Strathclyde, 204 George Street, Glasgow, G1 1XW, UK.

${ }^{2}$ Smarter Grid Solutions, Corunna House, 39 Cadogan Street, Glasgow, G2 7AB, UK.

${ }^{3}$ Scottish Hydro Energy Power Distribution, Inveralmond house, 200 Dunkeld Road, Perth, PH1 3AQ.
} 


\section{Introduction}

The challenges of operating a power system with large penetrations of intermittent and uncertain wind generation are well documented in the literature [1-3].These difficulties include the additional variation imposed on conventional generation by intermittency and uncertainty in wind, management of system frequency and network constraints due to the increased need to connect generation at distribution level. These issues are particularly acute in islanded power systems.

The UK has seen a number of important projects over the past five years dealing with the challenges that distributed renewable generation brings. Many of these are funded by the Low Carbon Network Fund [4] which encourages Distribution Network Operators (DNOs) to develop techniques that allow greater capacities of Distributed Generation (DG), particularly renewables, to connect to their networks.

In particular, DNOs are adopting Active Network Management (ANM) as a way of raising the capacity of DG above the traditional firm limit by modifying the existing conservative operating philosophy. A number of UK DNOs have already implemented the ANM concept, and all DNOs include it in their development plans for $2015-2023$ [5-8]. ANM in this context involves the connection of new DG under non-firm connection agreements (NF generation) where the DG developer is able to receive significantly cheaper and quicker connections to constrained distribution networks in return for agreeing to curtail output according to a well-defined principle of access. An ANM solution provides the necessary infrastructure to monitor, communicate with, and control generators and other network components. It also provides the intelligent systems which calculate required control actions including curtailment. Existing schemes use ANM to manage thermal and voltage limits on distribution networks including at their point of connection to the transmission network.

The Northern Isles New Energy Solutions (NINES) project on Shetland seeks to extend the ANM principle and apply it to the management of a small islanded distribution network [9-11]. Wind generation on Shetland has been limited to less than $4 \mathrm{MW}$ despite a demand range of $11 \mathrm{MW}-$ 45.5 MW and a very good wind resource (the main wind farm on Shetland claims a capacity factor of up to 0.52 [12]). Shetland is not connected to the wider UK electricity network and operates as an electrically islanded system. It suffers many of the operational issues associated with small power systems including low system inertia that can potentially lead to frequency instability if not managed effectively [13]. The $4 \mathrm{MW}$ limit on wind generation is in place to ensure that under all standard operating conditions the system can manage the loss of all wind generation without frequency breaching allowed limits. The NINES project aims to reduce the Shetland Islands' reliance on fossil fuel generation by using $\mathrm{ANM}^{4}$ to increase and control wind generation capacity. 
The NINES project also involves the connection of flexible domestic demand in the form of electric storage heaters and electric hot water heating with hot-water tanks. This Domestic Demand Side Management (DDSM) provides flexibility in the timing of electric energy delivery to the devices. The storage and immersion heaters have the ability to operate as Frequency Response Demand (FRD) which can further reduce curtailment by supporting the system during frequency deviations. NINES will include other flexible technologies including battery-based energy storage and other forms of demand management. Under NINES, the ANM concept is extended to include a day-ahead scheduling module that uses forecasts of wind generation and demand for the coming day to produce and implement schedules for flexible technologies that attempt to minimise fossil fuel generation by reducing curtailment of non-firm wind and minimise system losses.

The NINES project involves a range of innovations relevant to operating power systems with high penetrations of wind. Two notable innovations are the development and use of an 'envelope of stability for wind generation' and the use of Dynamic Optimal Power Flow (DOPF) to schedule flexible technologies. The envelope of stable wind generation is formed by the intersection of multiple linearised stability constraints which are functions of system demand. The frequency stability limit, which forms part of the envelope, requires detailed dynamic modelling of the power system. DOPF is an extension of Optimal Power Flow to cover multiple time-steps and produces a method of scheduling intertemporal flexibility - such as that provided by flexible demand - whilst taking full account of AC power flow limits and effects [14].

This paper provides a detailed overview of the modelling used in the development of the NINES project leading to deployment starting in 2013. It concentrates on the use of NF wind generation controlled by ANM and the use of DDSM. Other aspects of NINES such as the use of battery based energy storage are left for future work. Section 2 describes the general issues of stability in small power systems leading to a generic definition of the envelope of stable wind generation. Section 3 provides the details of the NINES study including the cases modelled in this paper. It describes the modelling carried out to specify the stability limits forming the stability envelope. Section 4 describes the DOPF scheduling methodology. Section 5 presents results showing the effect of non-firm wind capacity and flexible DDSM on fossil fuel generation, wind generation and system losses. Section 6 discusses the ability of DDSM to operate as FRD and presents results showing the additional effect FRD has on the system. Section 7 discusses the results and identifies an estimate of the likely 'viable' capacity of NF wind generation, and reduction in fossil fuel generation in each case. 


\section{Stability issues in the Shetland power system}

Small power systems suffer significant operational stability issues $[13,15]$. They are vulnerable to large fluctuations in frequency created by small power imbalances and tend to have a relatively small number of generation units online. As such the System Operator has a small number of available options for the provision of ancillary services such as spinning-reserve, whilst the need for those services at short notice is great. Maintaining stability is made more difficult by intermittent and uncertain wind generators; during normal operation they can add significantly to fluctuations in energy balance, and during transient faults wind turbines designed to operate as DG are likely to disconnect entirely. These issues are acute on Shetland, which must be operated in line with the requirements for UK distribution networks. The System Operator for Shetland has identified three related stability issues which are common to small islanded power systems: frequency stability; spinning reserve stability; and operational stability.

Frequency stability is defined as the ability of the system to respond in order to maintain frequency within a pre-defined limit during particular events. The definition of which events to secure against will vary between systems. Under the NINES project it is a requirement that frequency stability is maintained in the event of the instantaneous loss of all wind generation. This is a feasible event as the network is electrically small; a fault can affect a significant portion of the network for example by disconnecting breakers in the event of a short circuit. The connection arrangements of distributed wind generators in the UK are set by the G59 standard [16] and will be such that those generators are likely to disconnect in the event of extended voltage excursions. Whilst modern wind turbines have the ability to provide enhanced fault-ride through capabilities, these are not enforced on UK distribution networks.

Frequency stability depends on the inertia of the power system at the time of the event and the ability of the remaining generators to provide primary response through a fast increase in generation. The system will be more secure when more fossil-fuel units are online - frequency stability therefore tends to increases with system demand.

Spinning-reserve is closely related to frequency response. For a given dispatch of generation it refers to the headroom available from conventional generators currently online. Providing spinning reserve stability in the event of the loss of all wind generation means limiting wind generation to the current headroom at conventional plant. For a given dispatch of conventional generation, an increase in demand leads to a reduction in headroom and therefore a reduced limit on wind generation. Spinning reserve stability can be maintained through a combination of wind curtailment and the dispatch policy 
for conventional generators; for example bringing additional units online instead of curtailing wind generation.

Operational stability refers to the operation of conventional generation and any heuristic operating rules used by the system operator and developed through operational experience. In the case of NINES, operational stability relates to the Minimum Stable Generation (MSG) levels of conventional units. Where conventional units are required to provide frequency and spinning reserve stability, additional wind generation can only be accommodated by reducing the output from conventional units currently online. The minimum level at which they can be operated therefore sets a limit on wind generation. In analysis of the effect of wind on power systems, MSG has been shown to be critical [17].

These three concerns: frequency, spinning-reserve and operation stability together combine to define an envelope of stable operation which is illustrated in Figure 1 [18]. Stable operation of the network can be achieved in two ways: either by limiting the wind generation capacity to the maximum acceptable wind generation output during the minimum system demand, or connecting a greater capacity of wind and managing the output of that capacity, along with other network components, in real time to maintain generation within the envelope.

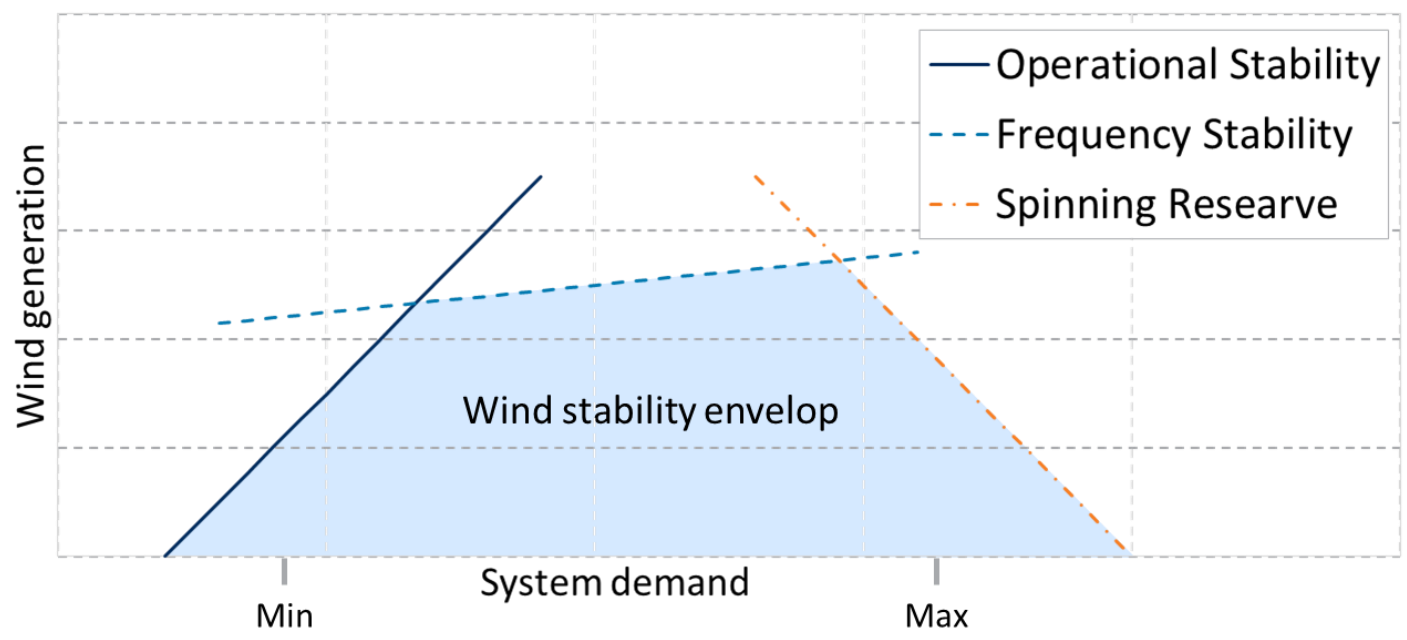

Figure 1: Illustration of the wind stability envelope restricting the operation of wind generation for a small islanded power system.

The NINES project also provides the opportunity to use DDSM to support system stability. The technology deployed can achieve this in two ways: through flexibility in the timing of demand and through the provision of frequency response to support frequency stability. Load shedding has traditionally been used to maintain frequency stability, particularly on islanded network, through Rate of Change of Frequency and underfrequency load shedding arrangements [19]. More recently, a 
number of studies have proposed that flexible demand can be used to manage stability in a more controlled way [20-22]. The use of DDSM to manage system stability in NINES is discussed in more detail in sections 4 and 6 .

\section{Shetland Case Study}

Shetland consists of 16 inhabited islands 100 miles north of the UK mainland with a population of approximately 22,000. Figure 2 shows (a) the geographical layout of Shetland and (b) the load duration curve of the electricity network.

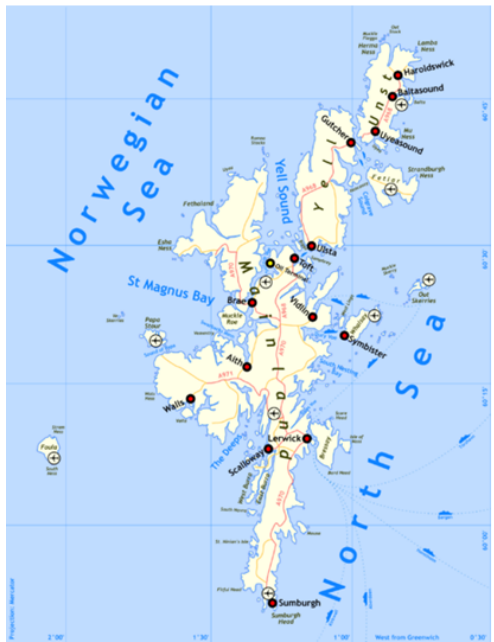

(a)

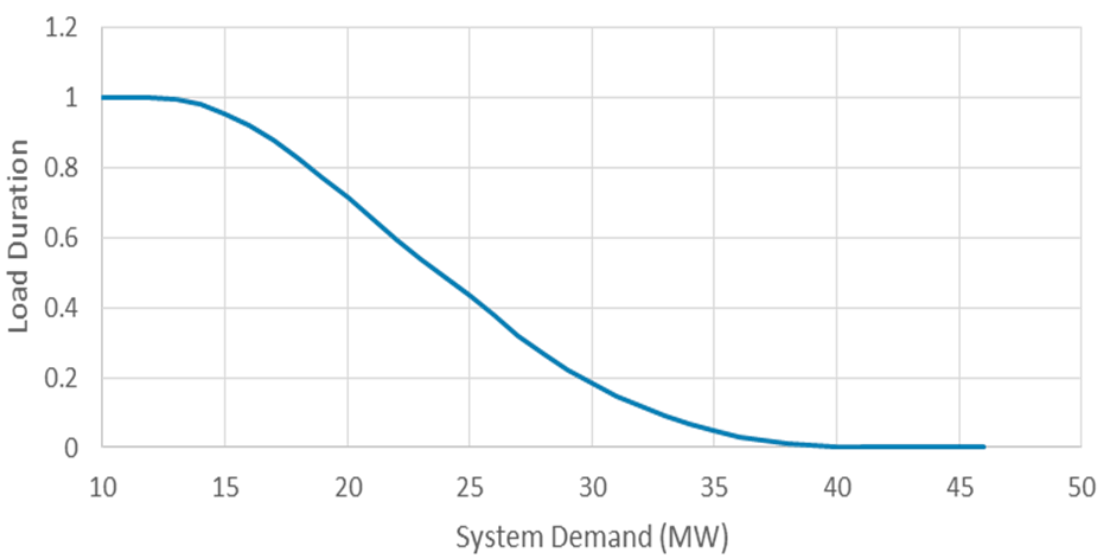

(b)

Figure 2: (a) the geographical layout of Shetland2; and (b) the load duration curve for 2010 - 11.

Currently electricity is generated at three main sites: Lerwick Power Station (LPS), Sullom Voe Terminal (SVT) and Burradale wind farm as well as a number of small community and micro generation sites. There are a number of significant changes that will take place to the Shetland power system over the coming few years. Foremost, LPS is due to be replaced in the next few years. There are a range of possible solutions to the challenge of repowering the Shetland electricity system, this paper concentrates on one which involves a new LPS with dual fuel reciprocating engines of approximately 9MW, burning either diesel or gas [23]. The replacement will be located close to the current LPS site and will be sufficiently sized to meet expected operational requirements. The development of NINES means that several new wind farm projects are expected to connect over the next few years, with a number currently applying for a non-firm network connection. The future status of generation from SVT is uncertain, and in this paper neither generation nor demand from SVT are included.

\footnotetext{
${ }^{2}$ Shetland map Creative Commons licence courtesy of http://commons.wikimedia.org/wiki/File:Wfm shetland map.png
} 
The NINES project has undertaken a wide ranging analysis of potential scenarios for the Shetland power system over the period 2015 - 2025, taking account of uncertainty in demand and generation scenarios as well as the prospects for major energy projects such as the proposed Viking Wind Farm [24]. This paper presents the results of one particular scenario representing one scenario for 2016 2017. This scenario is based on: historic demand from 2010 - 11, a repowered LPS, no generation or demand from SVT and no Viking Wind Farm. The focus of this paper is the use of DDSM to manage wind curtailment and provide frequency response; other aspects of NINES including battery energy storage are left for future work. Within this scenario the following 5 cases are modelled:

I. Base case without ANM: Existing firm wind generation only and no DDSM. This is the businessas-usual case and identifies wind generation, conventional generation and network losses against which to compare other cases.

II. New wind only: The addition of up to $20 \mathrm{MW}$ of new non-firm wind controlled by ANM is modelled. Wind is curtailed to maintain stability limits according to a Last-In-First-Off (LIFO) principle of access [25] where generators are prioritised according to their date of connection and low priority generators are always curtailed before high priority generators.

III. 250 flexible DDSM houses and new wind: Fixed electric heating is replaced with flexible electric heating for the initial expected roll out of DDSM on Shetland. Flexible demand means demand that can be scheduled to assist with energy balancing but does not provide frequency response.

IV. 1750 flexible DDSM houses and new wind: Fixed electric heating is replaced with flexible electric heating for a large but feasible roll out of DDSM.

V. 1750 frequency responsive DDSM houses and new wind: In addition to flexibility, the DDSM devices provide frequency response.

The case study uses historical data for wind generation and fixed electrical demand for two years: 2010 and 2011. The average historic capacity factor for Burradale over this period is 0.458 with 2010 representing a high wind year and 2011 a low wind year. Flexible electric demand profiles is estimated by detailed thermodynamic modelling. Table 1 summarises the case study set-up. An estimate of the potential non-firm capacity that maybe economically viable is made for each case using the assumption that generation achieving a capacity factor (CF) of 0.25 or higher will be viable; this limit is slightly lower than that of the entire UK wind fleet [26]. It should be noted that the assumption of fully correlated wind represents a worst-case scenario in terms of the expected levels of curtailment. This method will assume that all wind farms are operating close to full output at the same time. The actual level of correlation between wind farms will depend on their geographical separation, and the 
relatively small size of the Shetland network means that wind farms are likely to locate in close proximity.

Table 1: Specification of parameters for the case study

\begin{tabular}{|c|c|}
\hline LPS & $\begin{array}{ll}- & 12 \times 9 \mathrm{MW} \text { reciprocating engine units } \\
\text { - } & \text { Minimum stable output of units: } 20 \% \text { of rated capacity }(1.8 \mathrm{MW}) \\
\text { - } & \text { Units dispatched to provide capacity for existing demand level and } \mathrm{N}-1 \\
& \text { security (see section } 3.2 \text { ) }\end{array}$ \\
\hline $\begin{array}{l}\text { Wind } \\
\text { generation } \\
\text { profile }\end{array}$ & $\begin{array}{l}\text { All wind generation is assumed to follow the same uncurtailed profile as } \\
\text { Burradale based on historic records for } 2010-11 \text { (Fully correlated) }\end{array}$ \\
\hline Firm wind & $\begin{array}{l}\text { - } 4 \mathrm{MW} \text { located at Burradale. This models the existing generation at } \\
\text { Burradale and other small generation across the islands. }\end{array}$ \\
\hline Non-firm wind & $\begin{array}{ll}\text { - } & \text { New wind Connected at various locations up to 20MW (see Table 2) } \\
\text { - } & \text { Connect under LIFO principles-of-access }\end{array}$ \\
\hline SVT & Islanded; does not contribute demand or generation. \\
\hline DDSM capacity & $\begin{array}{l}\text { - Scenarios with 0, } 250 \text { and } 1750 \text { houses converted to DDSM located } \\
\text { across Shetland (see Table 2) }\end{array}$ \\
\hline DDSM demand & $\begin{array}{l}\text { - Estimated by detailed thermodynamic modelling of Shetland housing } \\
\text { stock [27]. }\end{array}$ \\
\hline Fixed demand & $\begin{array}{l}\text { - } \quad \text { Historic generation for the years } 2010 \text { and } 2011 \\
\text { - } \quad \text { For scenarios including DDSM, fixed demand is scaled down for each day } \\
\text { so that total energy demand (fixed and flexible) remains the same. }\end{array}$ \\
\hline
\end{tabular}


An overview of the Shetland 33kV Power network including the location of primary substations, generation and DDSM components is shown in Figure 3 and the distribution of (a) DDSM enabled houses and (b) wind generation is given in Table 2.

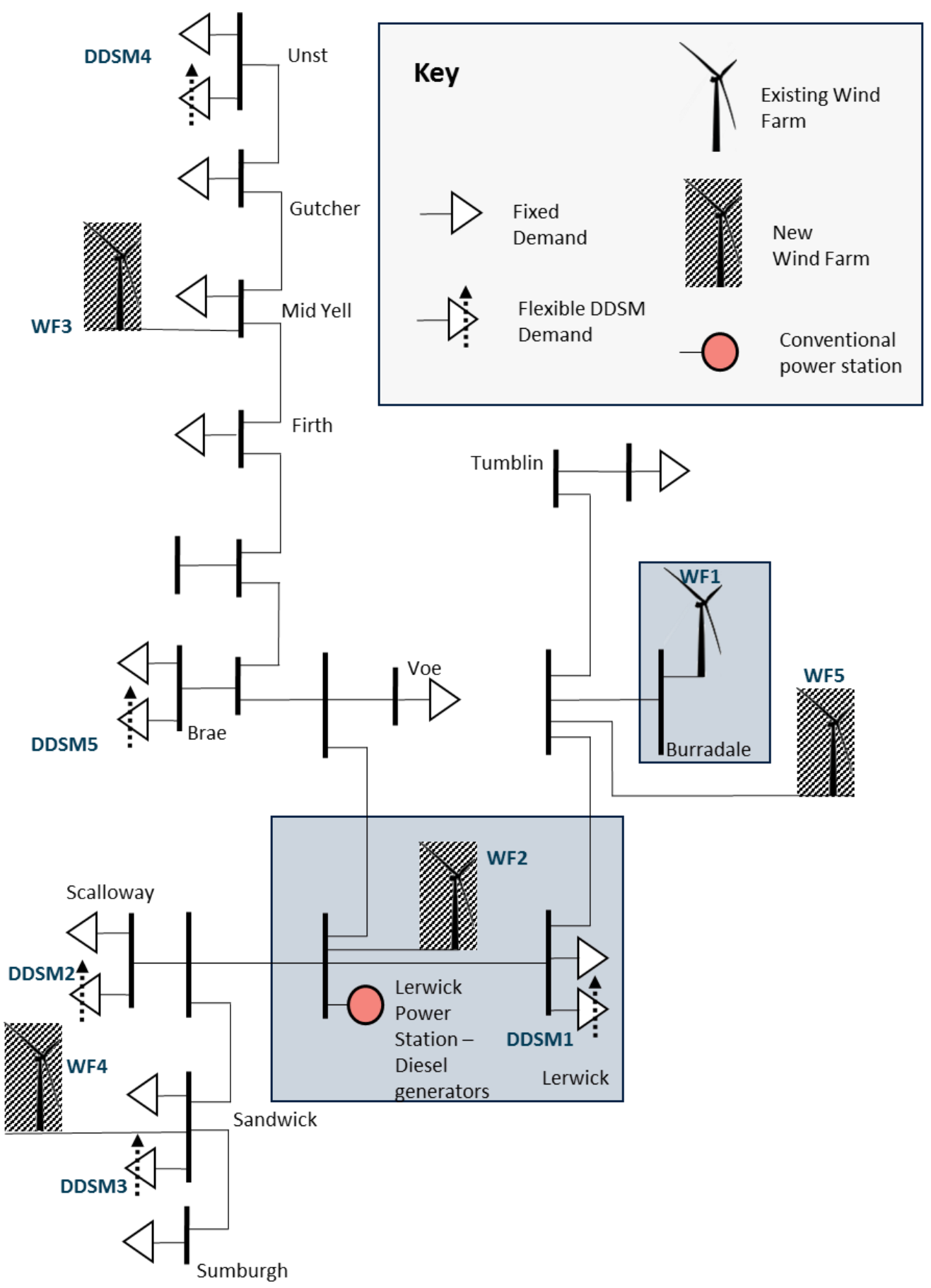

Figure 3: Outline of the Shetland power system showing the location of components used in the case study 
Table 2: (a) distribution of DDSM enabled houses for the case of 250 and 1750 houses together with total power and energy storage capacity of each location; (b) location, maximum capacity and LIFO priority order of wind farms

(a)

\begin{tabular}{|l|l|l|l|l|l|l|}
\hline & \multicolumn{3}{|l|}{250 DDSM houses } & \multicolumn{3}{l}{1750 DDSM houses } \\
& & & & \\
& Houses & MW & MWh & Houses & MW & MWh \\
\hline Lerwick & 170 & 1.38 & 6.83 & 1190 & 10.0 & 49.5 \\
& & & & & & \\
\hline Scalloway & 25 & 0.203 & 1.01 & 180 & 1.51 & 7.56 \\
\hline Sandwick & 15 & 0.122 & 0.603 & 105 & 0.882 & 4.41 \\
\hline Brae & 25 & 0.203 & 1.01 & 200 & 1.68 & 8.40 \\
\hline Unst & 15 & 0.122 & 0.603 & 75 & 0.168 & 0.48 \\
\hline
\end{tabular}

(b)

\begin{tabular}{|l|l|l|}
\hline Wind farm & $\begin{array}{l}\text { Max } \\
\text { Capacity } \\
\text { (MW) }\end{array}$ & $\begin{array}{l}\text { LIFO } \\
\text { priority }\end{array}$ \\
\hline & & N/A \\
\hline $\begin{array}{l}\text { Burradale } \\
\text { (Firm) }\end{array}$ & 4 & 1 \\
\hline Mid Yell & 4 & 2 \\
\hline Lerwick & 7 & 3 \\
\hline Sandwick & 5 & 4 \\
\hline Burradale NF & 4 & \\
\hline
\end{tabular}

The generic envelope of stable wind generation, illustrated in Figure 1, is defined specifically for the Shetland system modelled. Only two of the three limits are required for this case:

a. Operational Stability: defined by dispatching the number of LPS units based on a fixed security constraints and then applying a limit based on the MSG of these units.

b. Frequency stability: defined through detailed dynamic simulation of the power system and the requirement that nominal frequency limits of $+/-2 \%$ are maintained under the instantaneous loss of all wind generation.

The spinning-reserve limit is not required in this case as the dispatch of LPS units to maintain security ensures that, for all demand levels, there is sufficient spinning reserve to cover all wind generation.

A requirement of the software deployed in NINES is that the stability rules are defined in a linear form; defining the stability envelope therefore requires calculating appropriate parameters for each of the linear stability rules. Finally to operate the NINES ANM scheme, it must be possible to measure directly the variables which form the stability rules. System demand cannot be measured directly in real time and instead the total generation is used as a proxy for system demand. Total generation includes the output of LPS existing wind and NF wind.

\subsection{The Domestic Demand Side Management system}

Shetland does not have access to mains gas, and as such relies heavily on electric heating. A large number of domestic properties currently have heat provided by electric storage heaters and immersion heaters controlled via a basic teleswitching scheme which attempts to spread the load from these heaters across the day. The controllability provided is limited to 'on' and 'off' signal sent at the same time of day throughout the year. This is not appropriate for the NINES objective of supporting wind generation where the timing of available generation and expected curtailment will be different each day. The DDSM project aims to replace teleswitched storage and immersion 
heaters (and other forms of domestic heat provision such as solid fuels) with modern, highly insulated and controllable storage heaters and hot-water storage tanks with smart immersion elements. The initial roll out of smart heating systems in Shetland uses a variation of the Dimplex Quantum system [28]. These 'Shetland Quantum' devices are modern storage and immersion heaters which provide significantly improved level of controllability including the ability to respond to external signals sent from the ANM controller or other smart metering and communications systems. Storage heaters have significantly greater levels of insulation to reduce leakage losses; similarly the large, high temperature, high insulation hot-water tanks increase flexibility and reduce losses.

The modelling of DDSM presented in this paper accurately represents the roll-out of the technology to date on Shetland and plans for expansion of the scheme. Houses are retrofitted with smart electric storage heaters and smart immersion heaters with large, highly insulated water tanks. Houses will be allocated to groups, which are modelled here on a locational basis, with a group linked to a particularly electricity system bus. The centralised ANM system creates a forecast for underlying heat demand profile for each group for the coming 24 hours and represents the draw of heat out of the heaters into the house. This is based on forecasts of weather (temperature, wind, and solar irradiance), knowledge of the housing stock in each group - that is the number of houses of each type and size, and assumptions about occupancy patterns. This forecast for a heat demand profiles included leakage losses will be combined with measurements of the current State of Charge (SOC) of devices within each group to form the inputs to the Dynamic Optimal Power Flow.

To model the underlying heat demand profiles, this paper uses detailed finite-volume based thermodynamic modelling of both the heaters and the house. Space heating is modelled using ESP-r [29]. Firstly 34 house types representing the full range of building constructions, geometries and likely arrangement of heaters are created. Each 'house type' model includes the thermodynamics of the internal heater processes and accounts for the effect of leakage losses. House types are then modelled with variations in occupancy behaviours, comfort levels, and day types (e.g. weekday and weekend). Hot water heat-demand profiles are defined to reflect observed hot water consumption patterns [30] and 15-minute profiles are defined using the DHWcalc tool [31]. The final flexible demand profile at each DDSM location is created by simulating a representative set of house models (based on the local housing stock) against the historically recorded weather conditions for each day in the two year period January 2010 - December 2011. Figure 4(a) shows the total daily demand for energy for 1750 houses across the two years and highlights the strong seasonal pattern of heat demand with significantly lower demand in the summer months. It also shows the variability on a day-by-day basis due to variation in weather conditions. Figure $4(\mathrm{~b})$ shows the corresponding 15-minute resolution demand 
for heat across the first week of April 2010. More detail on the thermodynamic modelling methods used to define the heat-demand profiles are available in [32]. For each day in the case-study period, the SOC of the DDSM devices are modelled as starting and finishing the day at $50 \%$.

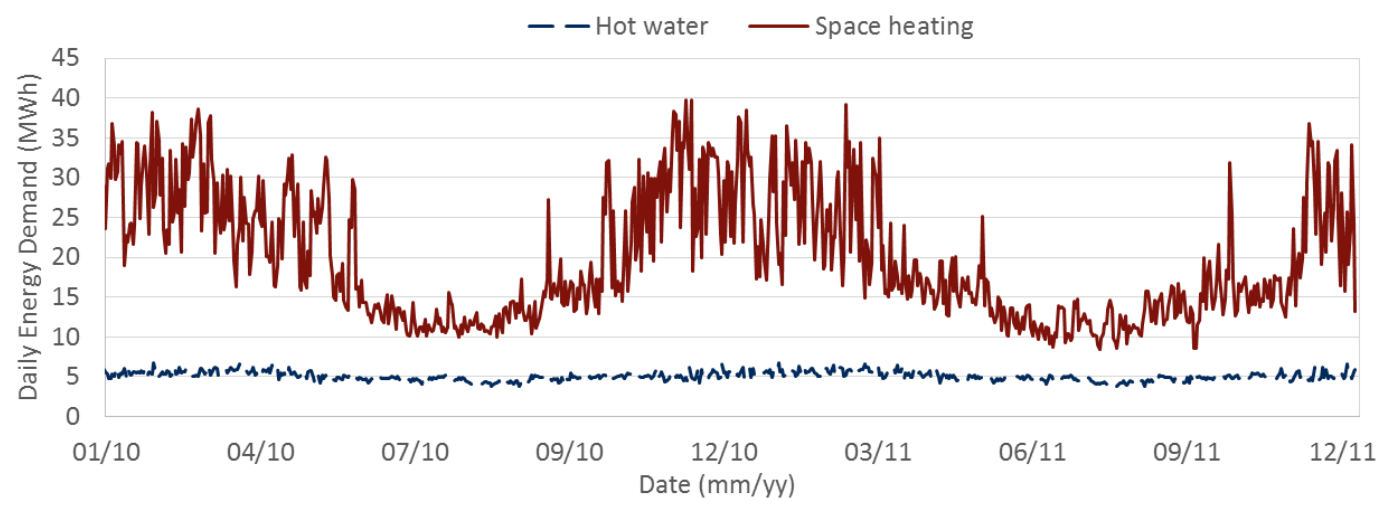

(a)

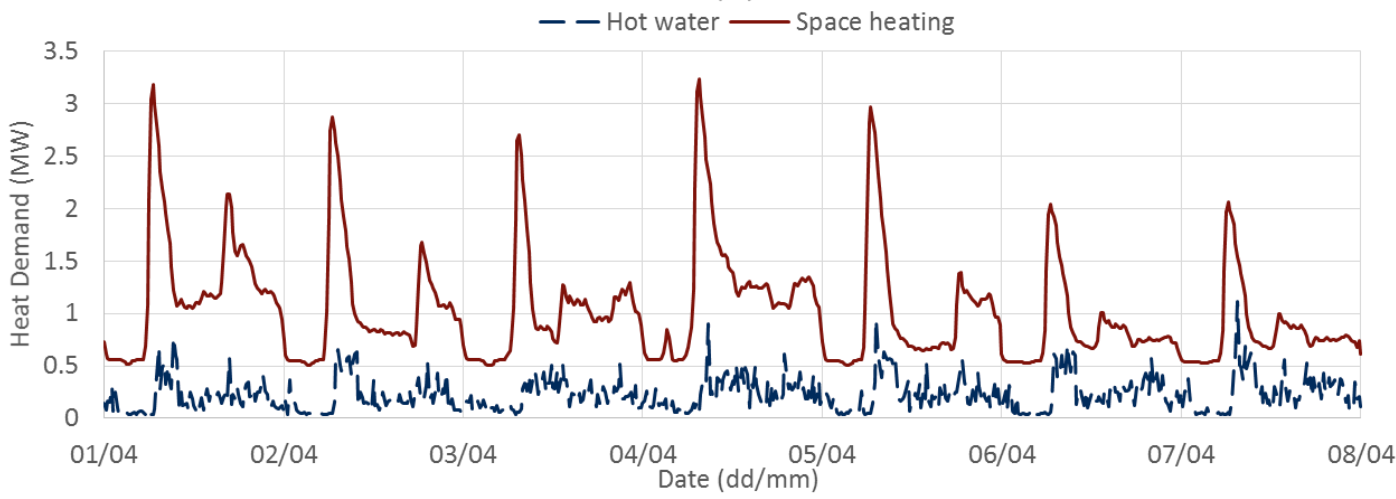

(b)

Figure 4: Demand profiles for hot water and space heating for 1750 DDSM enabled houses. (a) shows the daily energy demands plotted across two years; (b) shows the 15-minutes underlying heat demand profiles for the first week of April 2014.

\subsection{Defining the Operational Stability Limit in the Case Study}

The MSG of each reciprocating engine is assumed to be $20 \%$ of rated capacity - giving $1.8 \mathrm{MW}$ for each 9MW unit. LPS units are dispatched according to an $n-1$ contingency so that there is sufficient reserve available in the event that any 1 unit trips off. Mathematically for a given level of total generation, the number of units dispatched, $n_{L P S}$, is:

$$
n_{L P S}=\operatorname{int}\left\{\left(\frac{P_{g e n}}{9}\right)+2\right\}
$$


where $P_{\text {gen }}$ is the total system generation and $\operatorname{int}\{\cdot\}$ means to take the integer part of $\{\cdot\}$. Wind generation does not affect the number of units online, instead conventional units are backed-off towards their MSG. This sets a limit on wind generation of:

$$
P_{\text {wind }}^{\text {operational }}=P_{\text {gen }}-1.8 n_{\text {LPS }}
$$

This is a stepped function of demand with a discontinuity every $9 \mathrm{MW}$ and is shown in Figure 5 (a). This rule is linearised to ensure that the applied limit is less than (2) at all points:

$$
P_{\text {wind }}^{\text {operational }}=0.8 P_{\text {gen }}-3.6
$$

By dispatching conventional units in this way, there is always sufficient spinning reserve online to cover the loss of all wind generation.

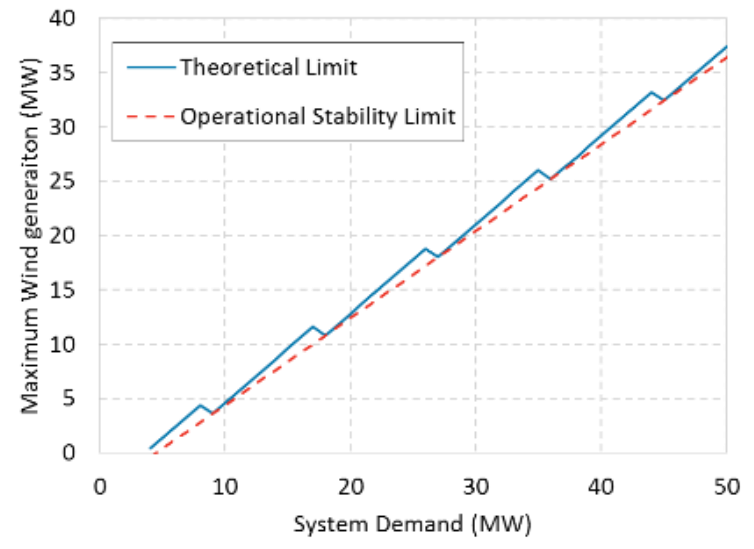

(a)

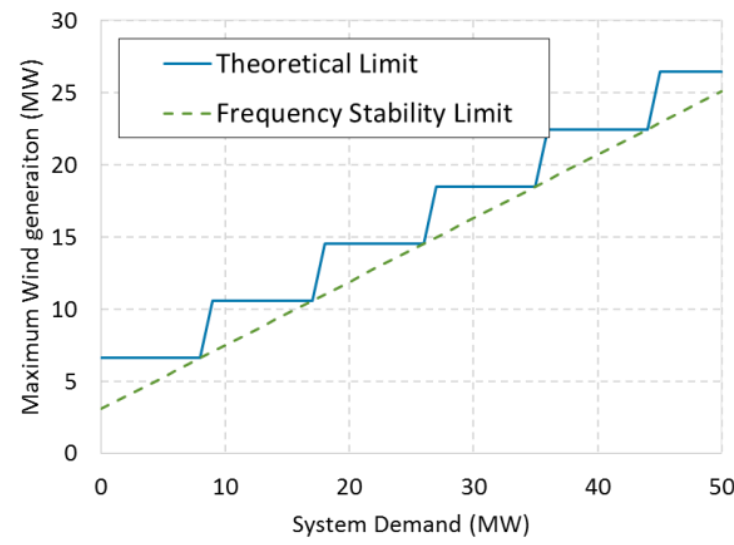

(b)

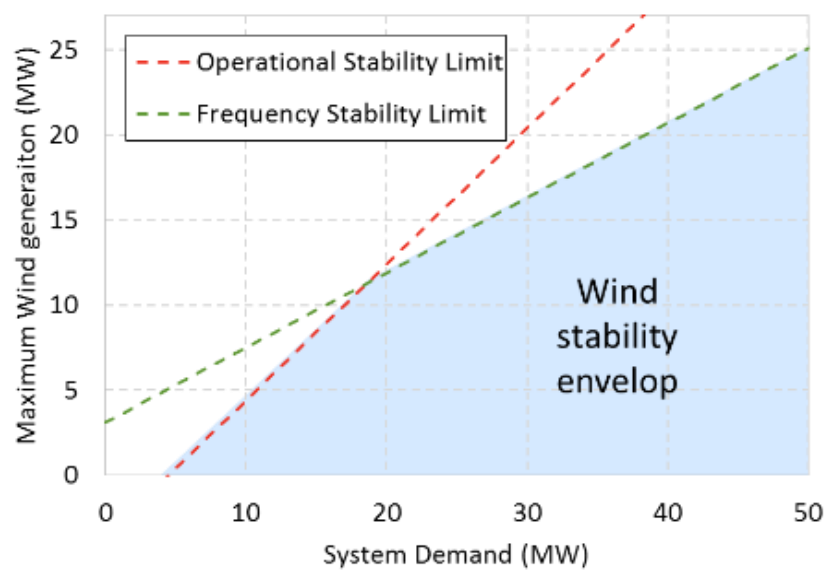

(c)

Figure 5: (a) Operational limit set by LPS unit dispatch and MSG, the solid line represents the theoretical limit and the dashed line shows the linear rule deployed in NINES; (b) frequency stability limit; and (c) the combined linear stability rules forming the wind stability envelop. 


\subsection{Defining the Frequency Stability limit in the Case study}

Defining frequency stability requires establishing the maximum loss of generation that maintains frequency within the nominal $+/-2 \%$ for a given set of conditions. This sets the maximum wind generation for those conditions. Power system dynamic modelling is carried out using the industry standard PSS/E modelling package [31] in which simulations are carried out in the time domain with high resolution. The 9MW reciprocating LPS units are modelled using generic round rotor synchronous generator models available in the PSS/E library (GENROU). Each generator model is equipped with an excitation system (ESAC5A) and governor (GAST) model which give a good representation of the turbine dynamics [31]. The parameters used in the models are taken from detailed dynamic models developed by the DNO for the existing Shetland system. These models have been extensively verified against frequency data recorded on Shetland during under-frequency events trigged by the loss of one or more generation units, and stabilisation of the system by the remaining units.

Wind generation, with capacity and locations as listed in Table 2 (b), is modelled using generic PSS/E wind turbine models. Dynamic simulations are used to find the maximum frequency deviation for a given loss of generation at a particular demand level assuming the LPS units are dispatched according to (1). A simulation consists of the following process for each specific demand and wind capacity:

1. Dispatch LPS units according to equation 1

2. Assume wind capacity operating at full output and reduce output of LPS units to accommodate wind generation

3. Run dynamic simulation with initial frequency set to $50 \mathrm{~Hz}$ and include an instantaneous trip of all wind generation at $t=1.5$ seconds.

4. Track system frequency over the following 13.5 seconds.

5. Identifying the minimum frequency

If the minimum system frequency is greater than $49 \mathrm{~Hz}$, the level of wind capacity is increased whilst demand is kept constant and the simulation is repeated. This process is itself repeated until the wind generation leading to a $2 \%$ drop in system frequency is identified. Figure 6 shows the response of the system to the loss of wind generation for the situation with total generation at $20 \mathrm{MW}$ and 4 LPS units online. At this demand level the maximum wind acceptable (including both firm and non-firm) within the frequency constraints is $14.9 \mathrm{MW}$.

Simulations are run with demand varied between 9MW and 50MW.The most important factor in determining frequency stability is the number of LPS units online as these provide the majority of system inertia and are the only source of primary frequency response. The actual stability limit is therefore a stepped function as illustrated in Figure 5 (b) and the linearised rule used to construct the 
wind stability envelop is defined to fall below the stepped function at all instances. The stability rule is as follows:

$$
P_{\text {wind }}^{\text {frequency }}=0.44 P_{\text {gen }}+3.1
$$

The section of the stability envelope defined by (3) and (4) is show in Figure 5 (c)

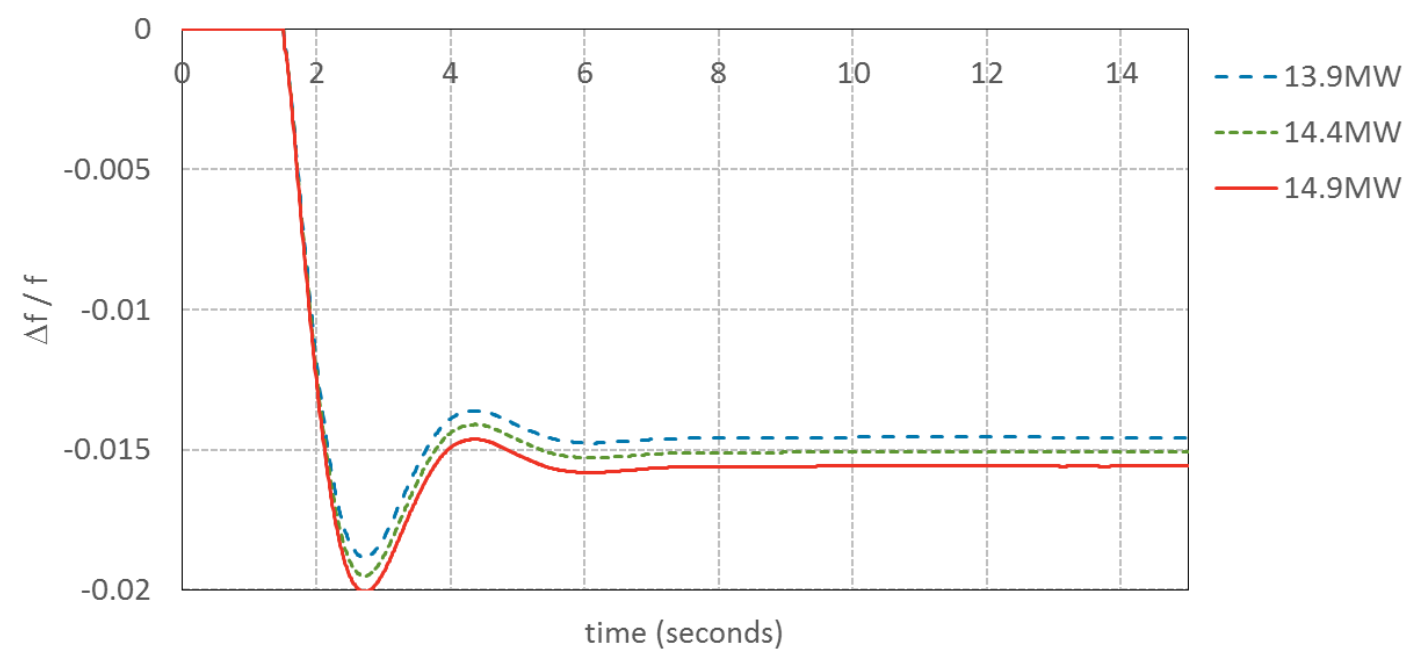

Figure 6: System frequency response with three wind penetrations and a total demand of 29MW. Results show that 14.9MW of wind generation is acceptable at this demand level

\section{Dynamic Optimal Power Flow scheduling}

The scheduling engine for the ANM scheme makes use of forecasts of wind generation, fixed demand and flexible demand for the coming 24 hours. It is run each day to produce a schedule for DDSM which ensures that the initial and final State Of Charge $(\mathrm{SOC})$ of the energy storage component of DDSM are the same, therefore delivering each day the energy used during that day, but providing flexibly over the timing of delivery.

In these studies a perfect foresight forecast is used in which it is assumed that wind generation and demand are perfectly predicted. Whilst this is not possible for real-time operation it provides two useful results: firstly it gives the maximum performance of the system; secondly it allows benchmarking of real forecasts. The effect of errors in forecasts is discussed in section 7 .

The model used to produce schedules for the ANM and DDSM schemes is based on a Dynamic Optimal Power Flow (DOPF) technique described in detail in [14]. DOPF extends Optimal Power Flow in the time domain linking a model of the power system at each time-step across a day with intertemporal flexibility, in this case provided by DDSM. 


\subsection{Formulation of DOPF model for Shetland}

The objective of the optimisation is to minimise conventional generation and smooth the profile required from LPS. This is achieved using a quadratic objective function, $f[14]$ :

$$
\min (f)=\sum_{t=1}^{96} P_{L P S}(t)^{2}
$$

where $P_{L P S}(t)$ is the power output of LPS during time-step $t$ and the day is divided into 96 time-steps. The LIFO priority order enforced by applying a small perturbation to the objective which adds a small cost associated with non-firm wind generation, and that cost is a linear function of the priority number, $p[14]$ :

$$
\min \left(f^{\prime}\right)=\sum_{t=1}^{96}\left(P_{L P S}(t)^{2}+\sum_{n=1}^{n_{n f}} \frac{p \cdot P_{N}(t)}{k}\right)
$$

Here $n_{n f}$ is the number of non-firm generators and $k$ is a constant whose value is chosen so that the second term is larger than the tolerance of the optimisation algorithm, but significantly smaller than the main term. This leads to a dispatch of wind according to LIFO principles of access without disrupting the main objective.

The DOPF includes a full AC-network model for each time-step which comprises of voltage limits, power flow limits, and minimum and maximum generator limits (see [14] for a full OPF formulation). In addition, intertemporal constraints are used to model demand flexibility at each DDSM group. The State of Charge $(\mathrm{SOC})$ of a group is an intertemporal variable defined as the fraction of total energy storage capacity currently used. The SOC at time $t$ is a function of the initial state of charge and the sum of the charging profile and heat demand profiles during all time-steps up to the current $t$ :

$$
\operatorname{SOC}(t)=\operatorname{SOC}(0)-\frac{\Delta t}{E_{D D S M}^{c a p}} \sum_{t^{\prime}=1}^{t} P_{D D S M}\left(t^{\prime}\right)-\frac{\Delta t}{E_{D D S M}^{c a p}} \sum_{t^{\prime}=1}^{t} P_{\text {Heat }}\left(t^{\prime}\right)
$$

Where $\Delta t$ is the length of a time-step, $E_{D D S M}^{c a p}$ is the total energy storage capacity of the DDSM group, $P_{D D S M}$ is the electrical charging power of the DDSM and $P_{\text {Heat }}$ is the underlying demand for heat, that is the draw of energy out of the thermal store.

The SOC of a group is constrained by the following:

$$
\begin{gathered}
0<S_{O O C_{D D S M}}(t)<S O C_{D D S M}^{\max } \forall t \\
\operatorname{SOC}_{D D S M}(0)=\operatorname{SOC}_{D D S M}\left(t_{n}\right)
\end{gathered}
$$




$$
0<P_{D D S M}(t)<P_{D D S M}^{\text {rated }}
$$

where $t_{n}$ is the final time-step of the optimisation and $P_{D D S M}^{\text {rated }}$ is the total rated electrical power capacity of devices within the group; (9) Maintains the SOC within limits during each time-step; (10) sets the initial and final SOC equal; and (11) ensures that the rate of chare is within limits.

Finally, network stability rules based on (3) and (4) are applied:

$$
\begin{gathered}
0.8 P_{\text {total }}(t)-3.6>P_{\text {wind }}(t) \\
0.44 P_{\text {total }}(t)+3.1>P_{\text {wind }}(t)
\end{gathered}
$$

Where $P_{\text {total }}(t)$ is the total generation (wind and conventional) on the system, and $P_{\text {wind }}(t)$ is the total wind generation (firm and non-firm).

\section{Results}

This section provides the results of applying the DOPF scheduling model, including the stability rules. Full numerical results are provided in the appendix.

\subsection{Case I- existing wind only}

The business-as-usual case assumes no demand flexibility, 4MW of firmly connected wind capacity with the remaining energy demand met by LPS. Over the two year period, total demand is 440.7GWh, and total generation is 444.9GWh with electrical losses accounting for $4.20 \mathrm{GWh}$ or $0.94 \%$ of generation. LPS generates $412.8 \mathrm{GWh}$ and firm wind $32.1 \mathrm{GWh}$ at an average capacity factor of 0.458 .

This represents expected results if the Shetland power system, under the assumptions proposed in this paper, were operated with no additional wind generation capacity and no ANM scheme. The following cases are compared against this base line.

\subsection{Case II- new wind only}

The addition of ANM allows NF wind to connect subject to curtailment. Studies are run for NF wind capacity ranging from $1 \mathrm{MW}$ to $20 \mathrm{MW}$ at the locations given in Table 2(b). NF wind is connected according to the LIFO priority order, with LIFO 1 connected first, LIFO 2 connected second etc. For example, a NF wind capacity of 10MW consists of 4MW at Mid-Yell (LIFO 1 fully connected), 6MW at Lerwick (LIFO 2 at partial capacity) and zero at Sandwick and Burradale NF (LIFO 3 and 4). The performance, after curtailment, of each additional MW of NF wind capacity can be expressed as the 
Marginal Capacity Factor (MCF), defined as the CF achieved by the last MW to connect. The MCF for Case II is shown in Figure 7(a). At low NF capacities, the MCF is close to the uncurtailed CF of 0.458 . Curtailment is applied to this high-priority capacity only occasionally during periods of exceptional low demand which coincide with high wind generation. With more than 7MW of NF capacity installed, the MCF falls as more curtailment is applied to lower priority generators. The $20^{\text {th }} \mathrm{MW}$ of NF wind capacity achieves a MCF of just 0.124 . In section 3 an estimate of economic viability was discussed which assumes that each unit of installed capacity must be able to achieve a CF in excess of 0.25 . Figure 7 (a) shows the capacity of NF wind generation that is viable under this definition. Using linear interpolation between the simulated points gives an estimate of the total viable NF capacity of 13.9MW. Full simulation results for this case are given in the appendix.

Total electrical losses are affected by the changing location of generation on the network as NF wind capacity increases. Total electrical losses are shown in Figure 7 (b). The change in losses as NF capacity increases depends on the location of the wind farm. From 1MW - 4MW capacity is added at Mid Yell and generation here during the majority of time-steps reduces the flow of power on the highly loaded line from Lerwick to Voe (see Figure 3). From 5MW - 11MW wind capacity is added at the same location as LPS and does not change power flows or network losses. From 12MW - 16MW wind capacity is connect at Sandwick and reduce power flows south from Lerwick. The remaining $4 \mathrm{MW}$ of wind capacity is added at Burradale and slightly increase losses as for the majority of timesteps power flow from Burradale to Lerwick is increased. 


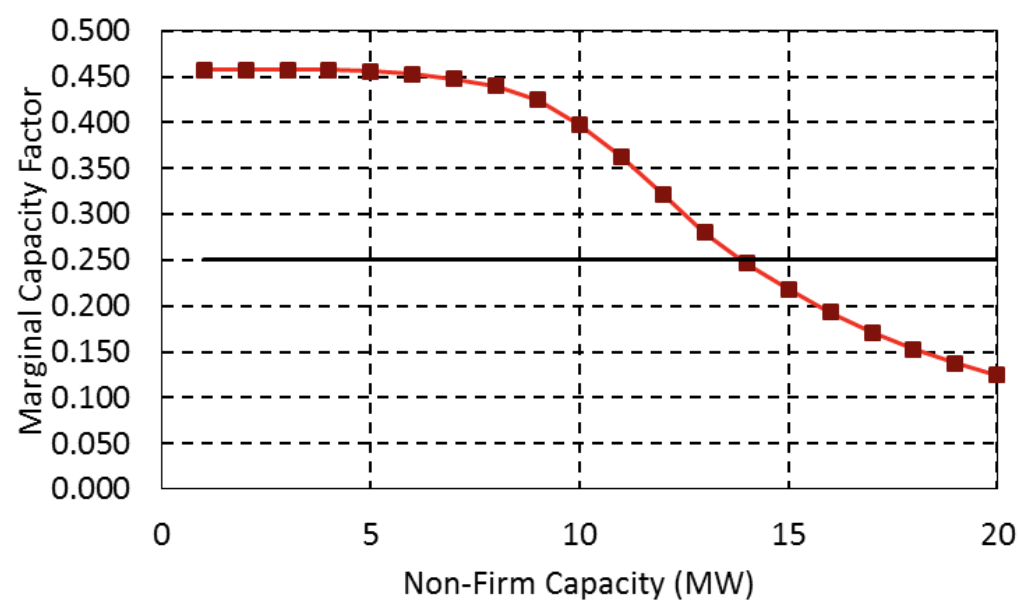

(a)

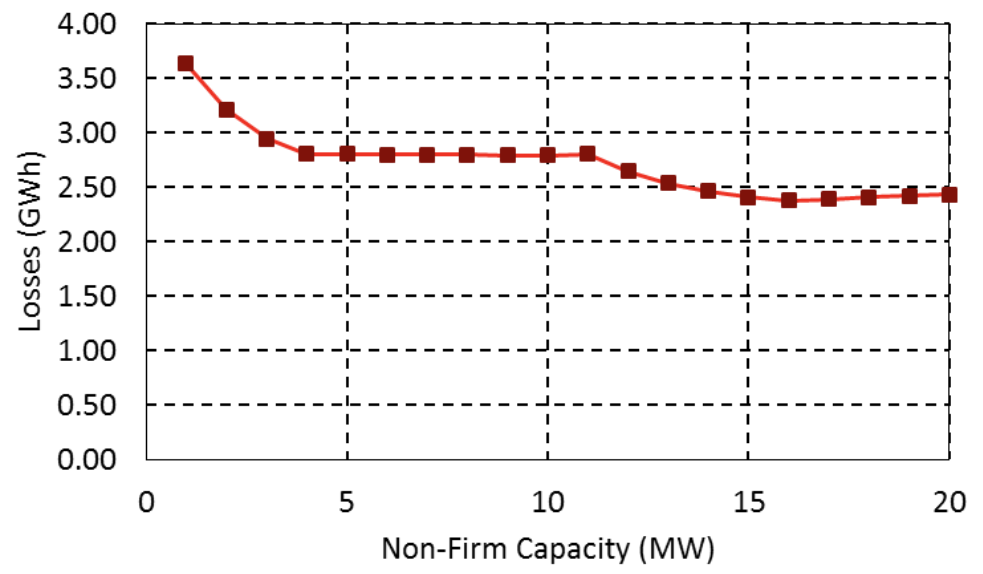

(b)

Figure 7: (a) Marginal capacity factor and (b) electrical losses for Case II with increasing capacity of non-firm wind generation.

\subsection{Case III - 250 flexible DDSM houses}

Case III represents the current expected roll out of DDSM on Shetland and assumes that DDSM is operated in flexible mode, without frequency response. The addition of 250 DDSM enabled houses allows the timing of approximately $1.5 \%$ of total electrical demand to be flexed within each day.

Results (given in the appendix) show that for a given NF generation capacity, wind generation increases compared with Case II. For example with 15MW of NF wind capacity, wind generation increases by $0.79 \mathrm{GWh}$ or close to $1 \%$. However, LPS output drops by $0.83 \mathrm{GWh}$ with the difference between these figures being due to the decrease in electrical losses. As well as reducing curtailment of NF wind, DDSM is scheduled at times of low load on the distribution network, therefore reducing 
total losses. On average, each DDSM enabled house therefore produces a reduction in conventional output of 3.31MWh/year.

Figure 8 gives an example of the output of the DOPF for two days. Firstly a winter day with low curtailment and high flexible energy demand. In this case DDSM demand cannot be met solely by reducing curtailment, instead remaining DDSM energy delivery is scheduled outside of peak hours therefore smoothing the demand curve and minimising electrical losses. In the second case, Figure 8 (b) there is excess curtailment, and delivery of DDSM energy is entirely scheduled in periods when excess wind generation can be used. During the winter day, the higher level of demand means that a greater capacity of energy storage is utilised with SOC varying from 1 (fully charge) to 0.22 ; this compares with a much small range of SOC used during the summer day - from 0.63 to 0.29 .

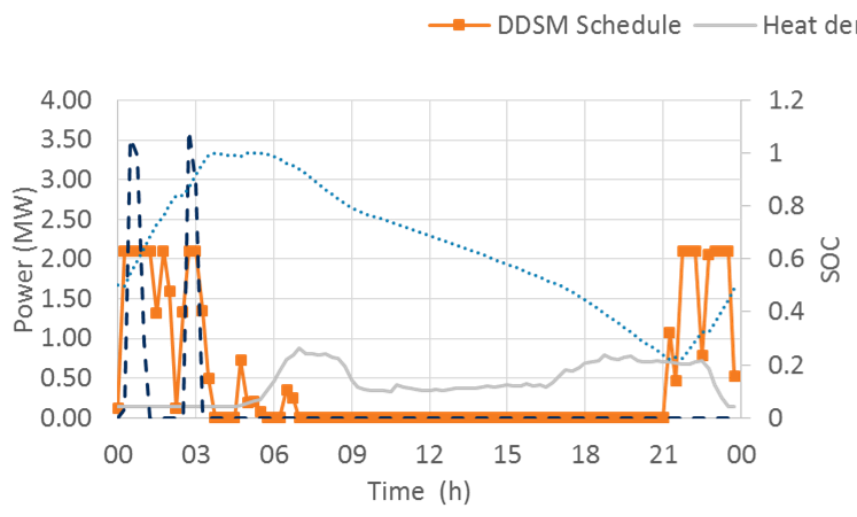

(a)

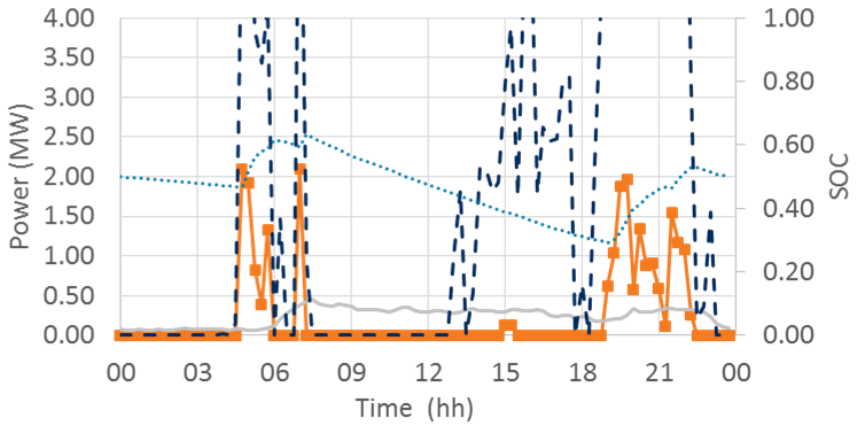

(b)

Figure 8: Two example days illustrating the scheduling of DDSM: (a) winters day with low curtailment and (b) a summers day with high curtailment. The graphs show the initial curtailment of wind before DDSM is deployed; the underlying demand for heat - that is the heat drawn out of the heaters; the DDSM schedule - that is the delivery of electrical energy to the heaters; and on the right hand axis the State of Charge.

\subsection{Case IV - 1750 flexible DDSM houses}

Case IV represents a large roll out of DDSM on Shetland, with flexible demand now representing $10 \%$ of total electrical demand. For 15MW of NF wind capacity, the addition of 1750 DDSM enabled houses increases wind generation by 3.41GWh, and decreases LPS generation by $3.57 \mathrm{GWh}$ compared with Case II. The value of each house in terms of reducing conventional generation is

\subsection{MWh/year.}

Figure 9 breaks down curtailment by month for 15MW of non-firm generation modelled in Case II (without DDSM) shown by the total bar height, and Case IV (1750 houses) shown by the solid bars. The initial level of curtailment is significantly higher during summer months. Whilst summer is less windy that winter, the lower electrical demand levels means there is greater curtailment. This graph, 
when compared with Figure 4 shows that curtailment and flexible demand are inversely correlated: when curtailment levels are high, flexible demand is low.

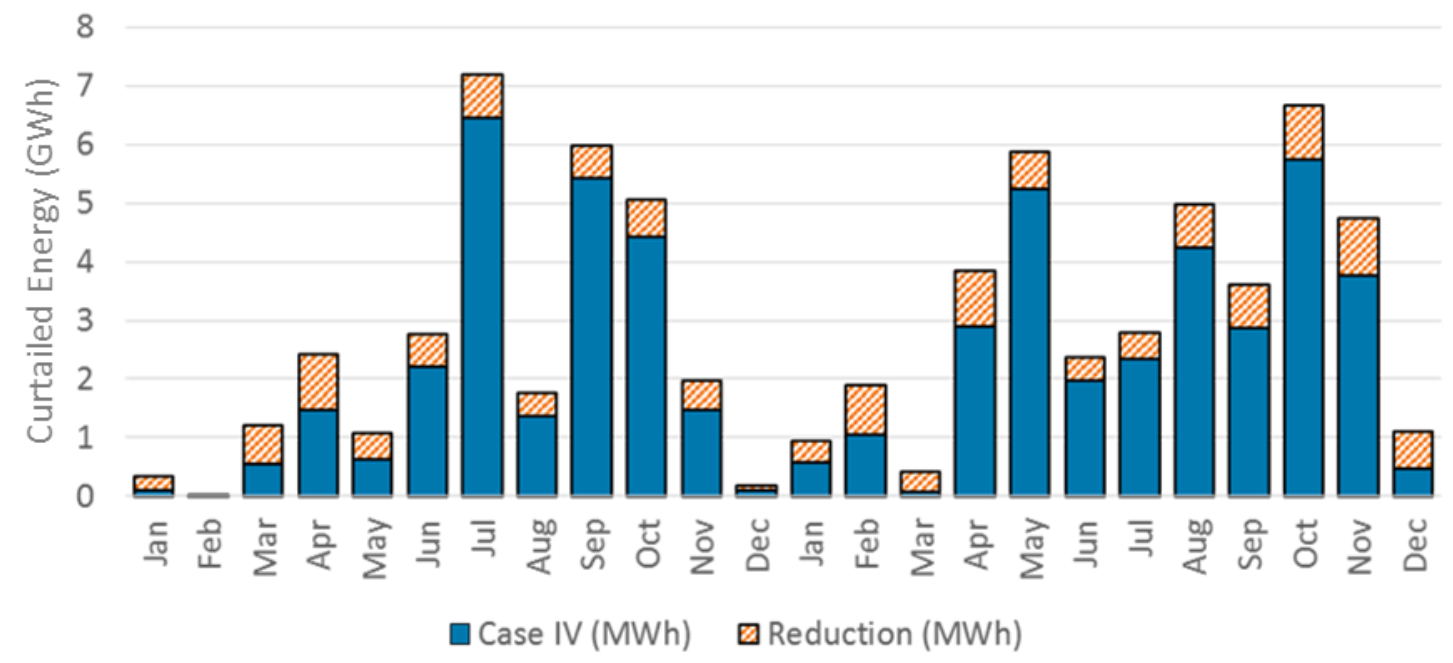

Figure 9: Curtailed energy by month for a non-firm wind capacity of 15MW. The full height of the bar represents the curtailment with no installed DDSM (Case II), the hatched area at the top of each bar is the reduction in curtailment created by 1750 DDSM houses.

\section{Frequency responsive demand}

The studies carried out in sections 5.1 - 5.4 allow the scheduling algorithm to choose the timing of demand flexibility so as to maximise wind generation. DDSM can also act in frequency responsive mode. To support the system, DDSM devices are capable of monitoring system frequency and responding to deviations away from $50 \mathrm{~Hz}$. Of importance in this paper is the ability of DDSM to reduce demand as frequency drops. This section describes the frequency responsive capability of DDSM, identifies its ability to relax the frequency stability limit, and shows the further decrease possible in conventional generation.

\subsection{Dynamic Modelling of the Shetland system with frequency responsive DDSM}

The frequency responsive characteristics of DDSM are set using a deadband and ramp rate as shown in Figure 10. The deadband is set to $+/-0.5 \mathrm{~Hz}$ and outside the deadband the ramp rate reduces demand to zero at $49 \mathrm{~Hz}$. The reduction in load below $49.5 \mathrm{~Hz}$ will support system frequency in the event of a loss of wind generation and therefore raise the frequency limit on wind generation for a given total demand level. 


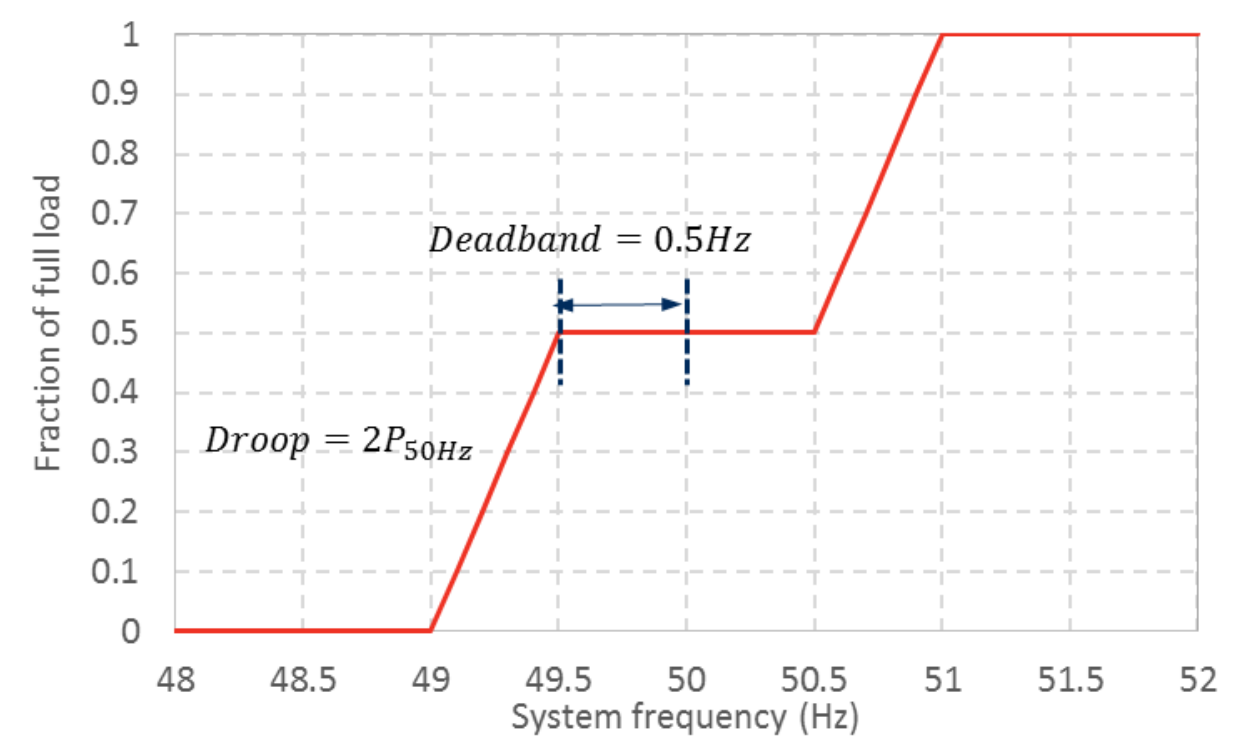

Figure 10: Response settings for Frequency responsive DDSM. A deadband is operated between $49.5 \mathrm{~Hz}$ and $50.5 \mathrm{~Hz}$. Outside the deadband the gradient of the droop curve is such that all FRD is removed when frequency drops to $49 \mathrm{~Hz}$.

Additional dynamic studies of the Shetland network incorporating FRD are carried out in PSS/E to identify the increase in wind generation acceptable for a given demand level. The following methodology is used:

1. For a given demand level and LPS dispatch, set wind capacity to the maximum stable wind generation calculated from simulations in Section 3.2.

2. Substitute $1.89 \mathrm{MW}$ (equal to the DDSM capacity of 250 houses) of existing demand for FRD.

3. Model the frequency response of the FRD according to the profile in Figure 10.

4. Run dynamic simulation with all wind instantaneously disconnected at $t=1.5$ seconds and track system frequency.

5. Identify the minimum frequency.

Steps $4-5$ are repeated with increasing wind capacity to identify the maximum wind generation which maintains frequency limits with the support of FRD.

The process is then repeated for FRD capacities up to $12.5 \mathrm{MW}$ which represents the total capacity of 1750 DDSM houses. Results are plotted in Figure 11 (a) and for 5 values of FRD. The results show that the effect of each unit of FRD is constant with total FDR penetration across the range of study. The gradient of the trend lines is constant and the increase in intercept is a linear function of the total FRD capacity enabled (see Figure 11(b)). The effect of FRD on the frequency limit is therefore modelled through an additional term related to the power drawn by FRD, $P_{F R D}$. The mean increase in maximum 
stable wind generation, $P_{\text {wind }}^{\max }$, from FRD is $0.35 \mathrm{MW}$ for each $1 \mathrm{MW}$ of FRD. Inequality (13) is therefore replaced with the following:

$$
0.44 P_{g e n}(t)+3.1+0.35 P_{F R D}>P_{\text {wind }}(t)
$$

Where, as before, $P_{g e n}(t)$ is the total system generation and is used as a proxy for total system demand.

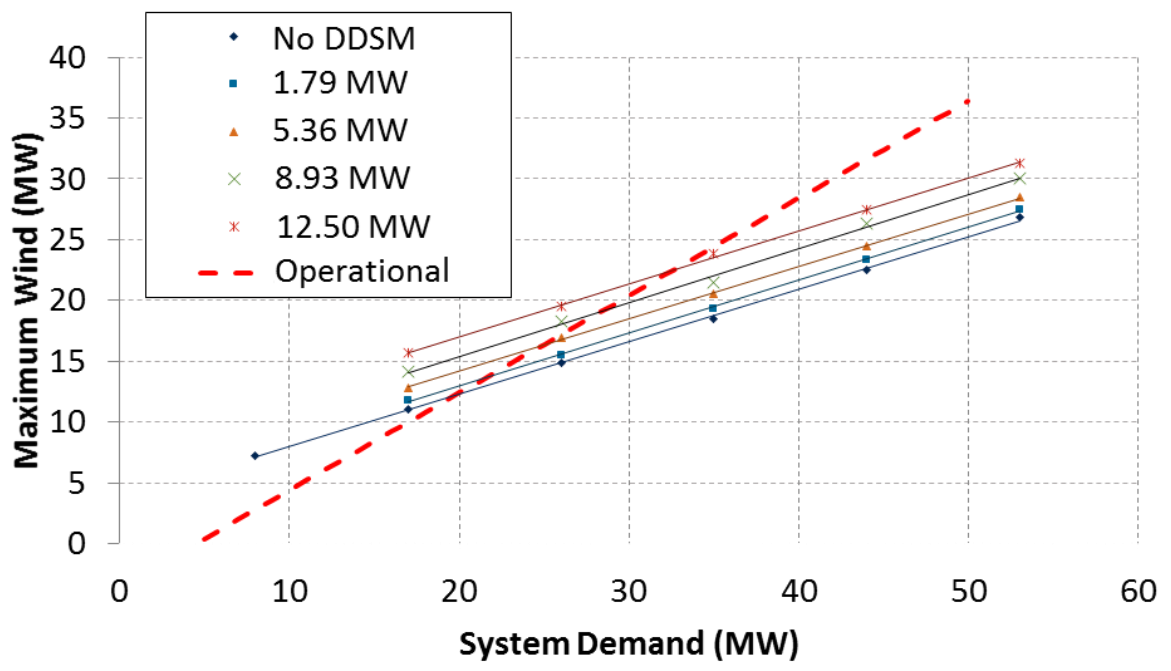

(a)

\begin{tabular}{llll}
\hline Trend & Gradient & Intercept & $\frac{\Delta c}{P_{D D S M}}$ \\
\hline No DDSM & 0.43 & 3.64 & $\mathrm{~N} / \mathrm{A}$ \\
\hline $\begin{array}{l}1.79 \mathrm{MW} \\
\text { (250 homes) }\end{array}$ & 0.44 & 4.24 & 0.335 \\
\hline $\begin{array}{l}5.36 \mathrm{MW} \\
\text { (750 homes) }\end{array}$ & 0.43 & 5.52 & 0.351 \\
\hline $\begin{array}{l}8.93 \mathrm{MW} \\
\text { (1250 homes) }\end{array}$ & 0.44 & 6.56 & 0.327 \\
\hline $\begin{array}{l}12.50 \mathrm{MW} \\
\text { (1750 homes) }\end{array}$ & 0.44 & 8.26 & 0.369 \\
\hline
\end{tabular}

(b)

Figure 11: Results of simulations for frequency limits including frequency responsive DDSM: (a) simulation results and linear trend-lines; and (b) parameters for trend lines including the increase in the intercept per MW of DDSM included in the simulation.

\subsection{Results: Case V - Frequency responsive DDSM}

To model the effect of FRD on required fossil fuel generation the case of 1750 DDSM enabled houses is repeated to include frequency response (Full results in appendix). For $15 \mathrm{MW}$ of installed wind capacity, wind generation increases by 7.13GWh compared to Case II (No DDSM) and 3.72GWh 
compared to Case IV (1750 Flexible DDSM houses); conventional generation drops by 7.31GWh compared to Case II and 3.74GWh compared to Case V. The addition of frequency response in this scenario therefore more than doubles the effectiveness of DDSM at reducing conventional generation.

When DDSM is operated in FRD mode, the DOPF algorithm schedules demand to be 'available' for frequency response. However, the frequency of faults leading to the need to activate the DDSM frequency response occur on the order of a few times a year. The dynamic studies, for example those shown in Figure 6 show that the frequency is stabilised within a few seconds allowing the DDSM devices to return to their scheduled demand level within a short time. In FRD mode, DDSM is therefore scheduled according to a different pattern than when simply providing flexibility in order to be 'availability' to respond, but it will only be actively deviating from its profile for a few tens of seconds per year. Providing the frequency response therefore does not significantly interfere with the load balancing defined in its schedule.

\section{Discussion}

The introduction of ANM allows a significant increase in installed wind capacity in the Shetland case study beyond the existing $4 \mathrm{MW}$ of firm wind capacity. With ANM in place, the limiting factor will be the economic viability of the projects and results suggest that this will be approximately 13.9MW. Beyond this, the introduction of DDSM has the potential to provide a further increase in generation from that capacity through management of curtailment, and therefore further reduce the Islands' reliance on fossil fuel generation. In effect, DDSM ensures more efficient use of NF wind capacity. As well as increasing generation from a particular capacity of wind, DDSM has the potential to raise the capacity that is likely to be economically viable. Figure 12 shows the MCF curves for cases II - V and the estimated limit on viability. The estimate of viable capacity rises from 13.9MW in Case II, to 16.1MW in Case V suggesting that 1750 DDSM enabled houses operating with frequency response can facilitated approximately an additional $2 \mathrm{MW}$ of economically viable NF wind capacity. It should be remembered that the precise definition of viability used here does not reflect the many factors that influence a decision on whether a particular project is viable, however it does give a useful estimate of the possible increase in viable capacity that DDSM can facilitate.

The use of DDSM can therefore reduce reliance on fossil fuel generation through three effects: increased viable NF capacity; increased generation from that NF capacity; and reduced electrical losses. A final study is run for each case with NF wind capacity set to the viable limit identified from Figure 12. Table 3 shows these results which represent the viable mix of renewable and conventional generation for each case and provide a single point of comparison for each case. 
The introduction of NF wind managed by ANM (Case II) reduces Shetland's reliance on fossil fuel by almost one quarter. With ANM in place, DDSM without frequency response can reduce fossil fuel reliance by $0.85 \mathrm{GWh}$ and $6.5 \mathrm{GWh}$ for 250 and 1750 houses respectively. If frequency response is enabled this rises to $16.6 \mathrm{GWh}$ for 1750 houses. In this final case, each house allows for a reduction in conventional generation of $4.63 \mathrm{MWh} /$ year compared with Case II. This is a significant fraction of household energy demand, representing $36 \%$ of the average annual household heat demand for the DDSM enabled houses. This reduction in conventional generation corresponds to a saving in fuel and carbon. As an order-of-magnitude estimate of the fuel savings, for a reciprocating engine burning fuel oil, a reduction in output of $4.63 \mathrm{MWh}$ equates to approximately $f 220$ in fuel savings ${ }^{3}$. This is a significant saving, and one which can be used to finance the cost of installing smart heating systems. A key issue in the UK electricity market is to find a way of commercially linking the consumer and generators. Financially, the beneficiary of additional flexible demand are the renewable generators through their increased ability to generate. Under the NINES project (and other UK distribution level ANM systems) non-firm generators are not compensated for curtailment, therefore an increase in their generation caused by DDSM leads directly to increased revenue from energy sales and subsidies. Setting up commercial structures which cater for a scheme that is DNO directed and consumer implemented represents a challenge that is as important as the technical solutions which must be developed to create a Smart Grid. One possible solution is to move towards a Distribution System Operator model (DSO) in which the DSO is able to facilitate local markets for energy and ancillary services. Such a model is currently being tested in a Danish distribution network on the island of Bornholm where a local market is created to manage network constraints and to interact with the Nordpool markets [34].

The savings discussed here represent the maximum effect of DDSM, and as noted earlier make use of the assumption of perfect foresight. In reality, schedules based on day-ahead forecasts of wind generation and demand will not achieve this optimal level. Work carried out by the Authors as part of [18] suggests that errors in wind forecasting for the Shetland system could reduce the effectiveness of scheduling by approximately $35 \%$. However, this should be placed against the likelihood that as the NINES system develops further, more sophisticated control and scheduling algorithms will be put in place. For example, it is likely that the simple day-ahead forecasting currently being implemented, will be replaced by systems which update schedules on a rolling base as more accurate forecasts, nearer to real-time, become available.

\footnotetext{
${ }^{3}$ Assumes: an energy conversion efficiency of $40 \%$ in the reciprocal generators; a net calorific value of $40 \mathrm{MJ} /$ litre for fuel; and a cost of oil of $£ 84 /$ Barrel.
} 
Another important effect is the role of customer engagement and perceptions of comfort. The heater controller on the DDSM project will override the ANM produced schedule if the SOC drops below pre-defined levels, or if the customer chooses to operate a separate 'boost button'. If consumers perceive that the heating system is not working, or if the scheduling algorithm is not accurate in predicting heat demand and providing energy when required, these overrides will reduce the effectiveness of the scheme at aligning electrical demand with the schedule. A number of studies have looked at customer engagement in demand side management. A world-wide review of such schemes for the UK Department of Energy and Climate Change [35] concludes that Demand Side Management is most effective when the control of demand is automated, as in the case of NINES. It also notes that accurate information and information on cost savings are important.

Finally, whilst the NINES project represents a solution to the particular problem of an Islanded distribution network, the solution has implications for power systems of all levels. On larger power systems, the control of large quantities of domestic FRD has the potential to participate in ancillary service markets for frequency response. The UK regulator, Ofgem, has reviewed the opportunities for wider demand-side participation in the UK electricity markets such as ancillary services, and notes that whilst there is the potential under the current market arrangements for increased demand side participation, work is needed to ensure a clear framework for interaction between customers, suppliers, network operators and generators and potentially aggregators [36].

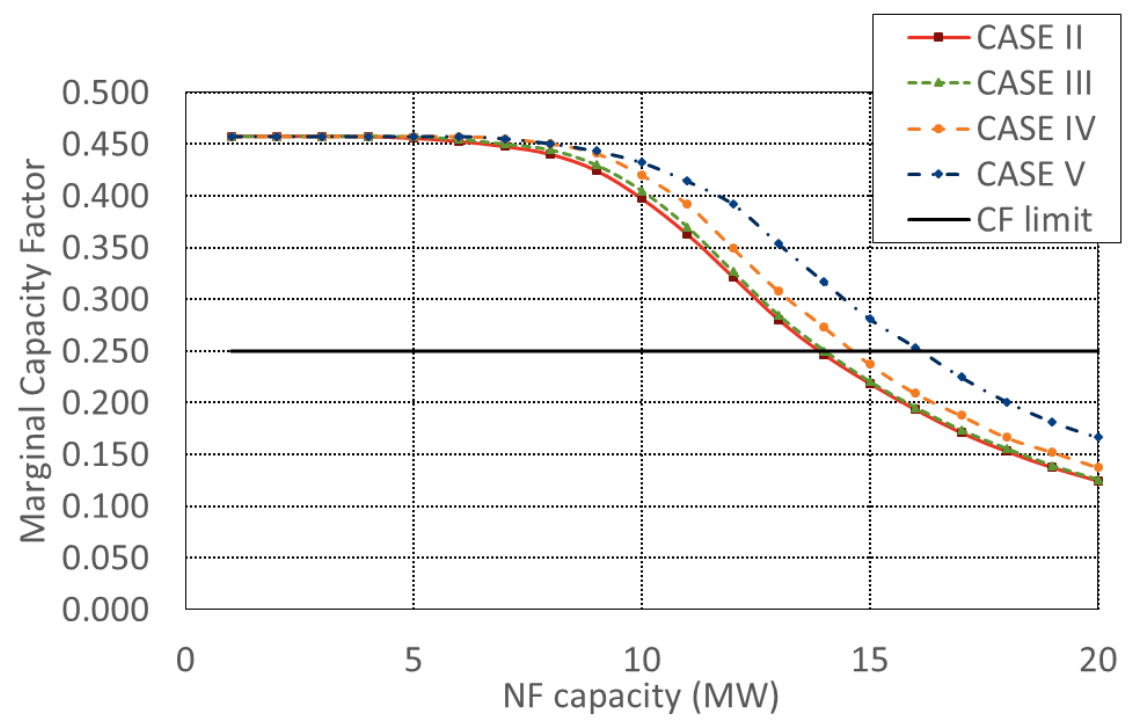

Figure 12: Marginal capacity factor for non-firm wind in cases II (new wind only), III (new wind and 250 DDSM enabled houses) and IV (1750 DDSM enabled houses) 
Table 3: The 'viable' wind capacity for each case, and generation totals

\begin{tabular}{|l|l|l|l|l|}
\hline Case & $\begin{array}{l}\text { Viable NF wind } \\
\text { capacity (MW) }\end{array}$ & $\begin{array}{l}\text { NF wind } \\
\text { generation (GWh) }\end{array}$ & $\begin{array}{l}\text { LPS generation } \\
\text { (GWh) }\end{array}$ & $\begin{array}{l}\text { Electrical } \\
\text { losses (GWh) }\end{array}$ \\
\hline Case I - No New Wind & 0 & 0 & 412.8 & 4.20 \\
\hline Case II - new wind only & 13.9 & 98.8 & 312.4 & 2.47 \\
\hline $\begin{array}{l}\text { Case III - 250 flexible DDSM } \\
\text { houses }\end{array}$ & 14.0 & 99.2 & 311.2 & 2.46 \\
\hline $\begin{array}{l}\text { Case IV - 1750 flexible DDSM } \\
\text { houses }\end{array}$ & 14.6 & 104.0 & 305.9 & 2.27 \\
\hline $\begin{array}{l}\text { Case V-1750 frequency } \\
\text { responsive DDSM houses }\end{array}$ & 16.1 & 115.1 & 295.8 & 2.21 \\
\hline
\end{tabular}

The modelling work presented here has informed the design and initial deployment of the NINES project on Shetland. Once in place, detailed monitoring of the operation of ANM will include high resolution measurements of wind generation output and the response of DDSM to scheduling. This is of particular importance as it will allow the impact of the assumptions used in this work to be tested including the assumption of fully correlated output of wind turbines; perfect foresight of wind generation and demand over 24 hour time horizons; and assumptions about how customers respond to DDSM controlled heating. Each of these assumptions represents a simplification of how the real system will operate that the authors judge to be suitable for the study presented and in line with other work in this field. The NINES project, once sufficient operational data has been collected, will therefore provide a useful opportunity to validate these assumptions or identify areas where greater sophistication is required.

\section{Conclusions}

The NINES project represents a state-of-the-art deployment of smart grid technologies on Shetland, particularly through its roll in combining technologies to meet one of the key aims of smart grid: the move towards a distributed, renewable power system. Deployment of the NINES system has involved the development of two novel modelling techniques: the definition of a stable envelope of wind generation and the use of Dynamic Optimal Power Flow. This paper has described these and presented their application in a particular case study of the Shetland power system. It has shown that the current $4 \mathrm{MW}$ of wind capacity connected on Shetland has the potential, through the use of ANM, rise to $13.9 \mathrm{MW}$. This increases to $14.6 \mathrm{MW}$ with management of flexible domestic demand and to $16.1 \mathrm{MW}$ with frequency responsive domestic demand. In energy terms, this corresponds to a reduction in reliance of fossil fuel generation of 100.4 GWh with ANM alone; up to an additional 6.5GWh from flexible domestic demand or $16.6 \mathrm{GWh}$ with frequency responsive domestic demand. 
This is achieved by reducing curtailment of wind generation under the control of ANM, increasing the capacity of wind generation that is economically viable and managing network losses.

\section{References}

[1] Ackermann, T.: 'Wind power in power systems' (Chichester:Wiley \& son, 2005)

[2] Morales, J.M., Conejo, A. J., Madsen, H., Pinson, P., and Zugno. M.: 'Integrating Renewables in Electricity Markets' (London: Springer, 2014)

[3] Jenkins, N., Allan, R., Crossley, P., Kirschen. D., and Strbac. G.: 'Embedded Generation' (London: IEE, 2000)

[4] Ofgem, 'Low Carbon Networks Fund', https://www.ofgem.gov.uk/electricity/distributionnetworks/network-innovation/low-carbon-networks-fund, accesded: 03/04/2014

[5] 'Smart Grid Strategic Review: The Orkney Island Active Network Management Scheme', (KEMA, 2012) Available at:

http://www.ssepd.co.uk/uploadedFiles/SSEPD Microsites/Orkney smart grid/

[6] SSE, "Facilitate Generation Connections on Orkney by Automatic Distribution Network Management" (Department of Trade and Industry, 2004)

[7] UKPower Networks, 'Low Carbon London' http://innovation.ukpowernetworks.co.uk/innovation/en/Projects/tier-2-projects/LowCarbon-London-(LCL)/, 03/04/2014.

[8] Ofgem, 'RIIO-ED1 Price Control', 2013, https://www.ofgem.gov.uk/network-regulation\%E2\%80\%93-riio-model/riio-ed1-price-control

[9] Dolan, M. J., Ault, G. W., Frame, D. F., Gill, S., Kockar, I., Anaya-Lara, O.: 'Northern Isles New Energy Solutions: Active Network Management Stability Limits', IEEE Inovative Smart Grid Technology Europe, Berlin, 2012.

[10] O'Neill, B., Foote, C., MacDonal, R., Dolan, M. J., Gill, S., Mathieson, C.: 'Active Network Management on Islanded Systems: The Shetland Experience', IEEE Inovative Smart Grid Technology Europe, Copenhagen, 2013.

[11] SHEPD, 'The NINES Smart Grid', http://www.ninessmartgrid.co.uk/, accessed: 20/01/2014.

[12] Shetland Aeorgenerators Limited, 'Burradale Wind Farm', http://www.burradale.co.uk/Projects.html, accessed: 03/04/2014.

[13] Horne, J., Flynn, D., and Littler. T.: 'Frequency stability issues for islanded power systems' in Power Systems Conference and Exposition, 2004. IEEE PES, 2004, pp. 299-306 vol.1.

[14] Gill, S., Kockar, I., and Ault, G. W.: 'Dynamic Optimal Power Flow for Active Distribution Networks', Power Systems, IEEE Transactions on, vol. 29, pp. 121-131, 2014.

[15] Kundur, P., Paserba, J., Ajjarapu, V., Andersson. G., Bose. A., Canizares, C., et al.: 'Definition and classification of power system stability IEEE/CIGRE joint task force on stability terms and definitions,' Power Systems, IEEE Transactions on, vol. 19, pp. 1387-1401, 2004.

[16] ENA, 'Distributed Generation Connection Guide. A guide for connecting generation to the distribution network that falls under G59/2', 2013. http://bit.ly/1bF1DMG accessed: 24/03/2014.

[17] DTI, 'The future value of storage in the UK with generator intermittency,' 2004.

[18] Gill. S., Ault, G., Kockar, I.: 'Using Dynamic Optimal Power Flow to inform the design and operation of active network management schemes', CIRED, Stockholm, June 2013.

[19] Mahat, P., Zhe, C., and Bak-Jensen, B.: 'Underfrequency Load Shedding for an Islanded Distribution System With Distributed Generators' Power Delivery, IEEE Transactions on, vol. 25, pp. 911-918, 2010.

[20] Pourmousavi, S. A., and Nehrir. M. H.: 'Real-Time Central Demand Response for Primary Frequency Regulation in Microgrids,' Smart Grid, IEEE Transactions on, vol. 3, pp. 1988-1996, 2012. 
[21] Kondoh, J., Ning, L., and Hammerstrom. D. J.: 'An Evaluation of the Water Heater Load Potential for Providing Regulation Service,' Power Systems, IEEE Transactions on, vol. 26, pp. 1309-1316, 2011.

[22] S. Gill, M. J. Dolan, D. Frame, and G. Ault, 'The Role of the Electric Heating and District Heating Networks in the Integration of Wind Energy to Island Networks,' International Journal of Distributed Energy Resources, vol. 7, pp. 245-262, July 20112011.

[23] SSE and URS, 'Replacement Lerwick Power Station Consent Applications and Environmental Impact Assessment', 2013.

[24] Viking Energy, Viking Energy - Harnessing Shetland's Natural Resources. Available: http://www.vikingenergy.co.uk/accessed: 12/12/2013.

[25] Baringa and UK Power Networks, 'Flexible Plug and Play - Principles of access report', 2013. Available at:

http://www.ukpowernetworks.co.uk/internet/en/innovation/documents/Principles_of_Acc ess_report_Final.pdf

[26] DECC, 'Digest of UK Energy Statistics (DUKES): Load factors for renewable electricity generation', 2012. Available:

http://www.decc.gov.uk/en/content/cms/statistics/energy_stats/source/renewables/reneb ables.aspx,

[27] Ault, G., Clarke, J., Gill, S., Hand, J., Kim, J., Kockar, I., Samuel, A., Svehla, K.: 'The use of simulation to optimise scheduling of domestic electric storage heating within smart grids', Building Simulation and Optimisation 2014, London.

[28] Dimplex, 'Introducing the Quantum Energy System', 2014, http://www.dimplex.co.uk/assets/kb/brochure/0/Quantum Brochure.pdf accessed: 30/09/2014

[29] ESRU, 'ESP-r overview', available at: http://www.esru.strath.ac.uk/Programs/ESPr overview.htm, accessed: 30/10/2014

[30] Energy Saving Trust, 'Measurement of domestic hot water consumption in dwellings', 2008. Available:

www.gov.uk/government/uploads/system/uploads/attachment data/file/48188/3147measure-domestic-hot-water-consump.pdf, accessed: 20/04/12.

[31] University of Kassel, 'DHWcalc Download', 2003. Available: www.solar.uni-kassel.de, accessed: 03/10/14.

[32] Clarke, J.C., Hand, J., Kim, J-M., Samuel, A., Svehla, K., 'Electricity storage within the domestic sector as a means to enable renewable energy integration within existing electricity networks', 13th Conf. Int. Building Performance Simulation Association, Chambery, France.

[33] Siemens, 'PSSE Produce Suit', 2014, Available at: http://www.energy.siemens.com/hq/en/services/power-transmission-distribution/powertechnologies-international/software-solutions/pss-e.htm

[34] EcoGrid EU, 'EcoGrid EU: From Design to Implementation', 2013. http://www.euecogrid.net/images/News/131004 \%20edk\%20a4 ecogrid\%20eu\%20project web.pdf accessed: 30/10/2014

[35] DECC, 'Demand Side response in the domestic sector - a literature review of major trials', 2012, Available at: https://www.gov.uk/government/uploads/system/uploads/attachment data/file/48552/57 56-demand-side-response-in-the-domestic-sector-a-lit.pdf Accessed: 03/10/2014

[36] Ofgem, 'Creating the right environment for demand-side response: next steps', 2013, Available at : https://www.ofgem.gov.uk/ofgempublications/85129/creatingtherightenvironmentfordemandsideresponsenextsteps.pdf Accessed: 03/10/2014 


\section{Appendix}

Table 4: Results showing LPS generation, total non-firm wind generation, marginal capacity factor and electrical losses for the Cases II - III. Results should be compared with the values given in Section 5.1 for Case I representing the base case of no additional wind generation and no DDSM.

\begin{tabular}{|c|c|c|c|c|c|c|c|c|c|c|c|c|c|c|c|c|}
\hline \multirow[b]{2}{*}{ 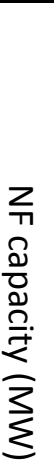 } & \multicolumn{4}{|c|}{ Case II: New Wind Only } & \multicolumn{4}{|c|}{ Case III: 250 houses } & \multicolumn{4}{|c|}{$\begin{array}{l}\text { Case IV: } 1750 \text { flexible DDSM } \\
\text { houses }\end{array}$} & \multicolumn{4}{|c|}{$\begin{array}{l}\text { Case V: } 1750 \text { Frequency } \\
\text { Responsive DDSM houses }\end{array}$} \\
\hline & 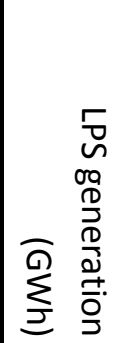 & 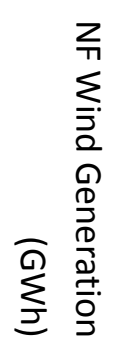 & 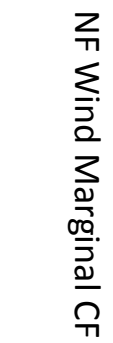 & 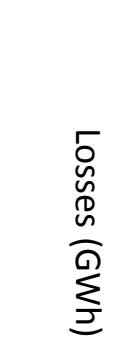 & 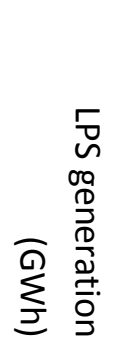 & 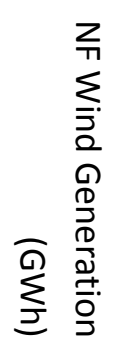 & 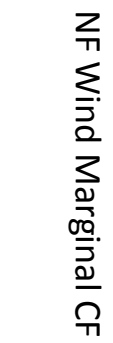 & 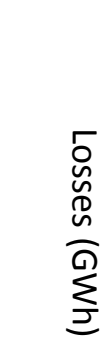 & 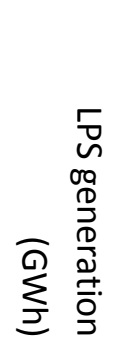 & 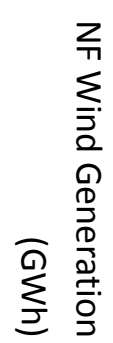 & 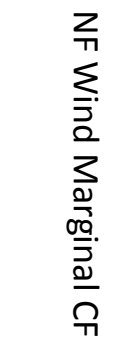 & 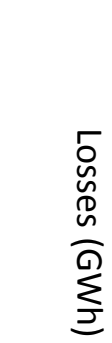 & 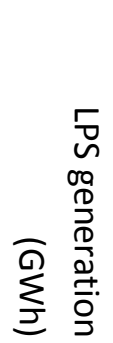 & 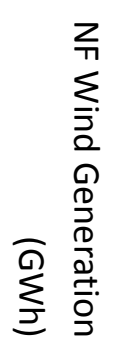 & 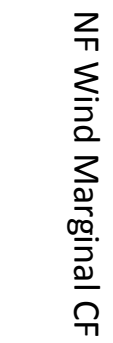 & 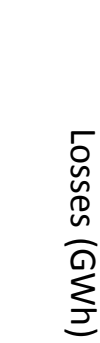 \\
\hline 1 & 404.3 & 8.0 & 0.458 & 3.63 & 404.2 & 8.0 & 0.458 & 4.20 & 404.2 & 8.0 & 0.458 & 4.13 & 404.2 & 8.0 & 0.458 & 3.55 \\
\hline 2 & 395.8 & 16.0 & 0.458 & 3.22 & 395.8 & 16.0 & 0.458 & 4.20 & 395.7 & 16.0 & 0.458 & 4.13 & 395.7 & 16.0 & 0.458 & 3.12 \\
\hline 3 & 387.5 & 24.1 & 0.458 & 2.94 & 387.5 & 24.1 & 0.458 & 4.20 & 387.4 & 24.1 & 0.458 & 4.13 & 387.4 & 24.1 & 0.458 & 2.84 \\
\hline 4 & 379.4 & 32.1 & 0.457 & 2.81 & 379.4 & 32.1 & 0.458 & 4.20 & 379.3 & 32.1 & 0.458 & 4.13 & 379.3 & 32.1 & 0.458 & 2.68 \\
\hline 5 & 371.4 & 40.1 & 0.456 & 2.81 & 371.3 & 40.1 & 0.457 & 3.61 & 371.2 & 40.1 & 0.458 & 3.55 & 371.2 & 40.1 & 0.458 & 2.68 \\
\hline 7 & 355.6 & 55.8 & 0.448 & 2.80 & 355.5 & 55.9 & 0.450 & 2.92 & 355.2 & 56.1 & 0.455 & 2.84 & 355.2 & 56.1 & 0.455 & 2.68 \\
\hline 8 & 347.9 & 63.5 & 0.440 & 2.80 & 347.7 & 63.7 & 0.445 & 2.78 & 347.4 & 64.0 & 0.451 & 2.69 & 347.3 & 64.0 & 0.451 & 2.68 \\
\hline 9 & 340.5 & 71.0 & 0.425 & 2.80 & 340.2 & 71.3 & 0.431 & 2.77 & 339.6 & 71.7 & 0.442 & 2.66 & 339.6 & 71.7 & 0.443 & 2.68 \\
\hline 10 & 333.5 & 77.9 & 0.397 & 2.80 & 333.1 & 78.3 & 0.406 & 2.86 & 332.3 & 79.1 & 0.421 & 2.75 & 332.0 & 79.3 & 0.432 & 2.68 \\
\hline 11 & 327.2 & 84.3 & 0.363 & 2.81 & 326.6 & 84.8 & 0.372 & 3.02 & 325.4 & 85.9 & 0.394 & 2.92 & 324.8 & 86.6 & 0.414 & 2.69 \\
\hline 12 & 321.4 & 89.9 & 0.322 & 2.65 & 320.7 & 90.6 & 0.328 & 2.81 & 319.1 & 92.1 & 0.351 & 2.71 & 317.7 & 93.4 & 0.392 & 2.50 \\
\hline 13 & 316.3 & 94.8 & 0.280 & 2.54 & 315.6 & 95.5 & 0.286 & 2.68 & 313.6 & 97.5 & 0.309 & 2.57 & 311.4 & 99.6 & 0.354 & 2.37 \\
\hline 14 & 312.0 & 99.2 & 0.246 & 2.46 & 311.2 & 99.9 & 0.251 & 2.60 & 308.7 & 102.2 & 0.274 & 2.48 & 305.7 & 105.2 & 0.317 & 2.28 \\
\hline 15 & 308.1 & 103.0 & 0.218 & 2.41 & 307.2 & 103.8 & 0.221 & 2.55 & 304.5 & 106.4 & 0.238 & 2.43 & 300.8 & 110.1 & 0.281 & 2.23 \\
\hline 16 & 304.7 & 106.4 & 0.193 & 2.38 & 303.8 & 107.2 & 0.196 & 2.52 & 300.8 & 110.1 & 0.210 & 2.40 & 296.3 & 114.6 & 0.254 & 2.21 \\
\hline 17 & 301.7 & 109.4 & 0.171 & 2.39 & 300.8 & 110.2 & 0.174 & 2.53 & 297.5 & 113.4 & 0.188 & 2.41 & 292.4 & 118.5 & 0.225 & 2.23 \\
\hline 18 & 299.0 & 112.1 & 0.153 & 2.41 & 298.1 & 113.0 & 0.155 & 2.55 & 294.6 & 116.3 & 0.167 & 2.43 & 288.9 & 122.0 & 0.201 & 2.25 \\
\hline 19 & 296.6 & 114.5 & 0.137 & 2.42 & 295.6 & 115.4 & 0.139 & 2.56 & 292.0 & 118.9 & 0.152 & 2.45 & 285.7 & 125.2 & 0.181 & 2.27 \\
\hline 20 & 294.4 & 116.6 & 0.124 & 2.44 & 293.5 & 117.6 & 0.125 & 2.58 & 289.6 & 121.4 & 0.138 & 2.47 & 282.8 & 128.1 & 0.166 & 2.30 \\
\hline
\end{tabular}

